\title{
Inhibitory effect on acetylcholinesterase and toxicity analysis of some medicinal plants
}

\author{
Mehmet Emin Diken (i) 1,*, Begumhan Yilmaz Kardas ${ }^{(i)}$
}

${ }^{1}$ Balikesir University, Science and Technology Application and Research Center, Balikesir, Turkiye

${ }^{2}$ Balikesir University, Faculty of Science and Literature, Department of Molecular Biology and Genetics, Balikesir, Turkiye

Abstract: This study aimed to analyse the inhibition of different extracts of Rosmarinus officinalis, Pistacia terebinthus and Sideritis dichotoma on acetylcholinesterase enzyme of Drosophila melanogaster. Additionally, the biological features including antioxidant activity, phenolic contents, antibacterial effects and in vivo toxicities were identified using radical scavenging, FolinCiocalteu, disc diffusion methods, and larval (eclosion) assay using Drosophila, respectively. Also, GC-MS was used to determine of the terpene-derivative compositions of the plants. $\mathrm{IC}_{50}$ values on acetylcholinesterase were determined between $0.57 \pm 0.02-2.54 \pm 0.11 \mu \mathrm{g} \mu \mathrm{L}^{-1}$ for ethanol, $0.86 \pm 0.05-2.19 \pm 0.15 \mu \mathrm{g} \mu \mathrm{L}^{-1}$ for methanol and $1.98 \pm 0.13-4.76 \pm 0.24 \mu \mathrm{g} \mu \mathrm{L}^{-1}$ for water extracts. Inhibition types of Rosmarinus, Pistacia and Sideritis were uncompetitive, competitive and competitive, respectively. The antioxidant activities of the extracts were between $77.87 \pm 1.72-96.94 \pm 1.84 \%$ against DPPH and $90.57 \pm 2.18-98.18 \pm 2.36 \%$ against $\mathrm{ABTS}^{+}$radicals. GC/MS results showed that carvacrol and thymol were the major monoterpenes of Pistacia and Sideritis, while limonene and borneol were the main monoterpenes of Rosmarinus. The strongest antibacterial activities were observed with Rosmarinus and Sideritis against Staphylococcus aureus and Escherichia coli, respectively with an inhibition zone larger than $15 \mathrm{~mm}$. According to the in vivo toxicity study, all extracts were found non-toxic to Drosophila, and they ameliorated $\mathrm{H}_{2} \mathrm{O}_{2}$ induced decrease of puparation, survival rate and eclosion values.

\section{ARTICLE HISTORY}

Received: Dec. 05, 2021

Revised: Jan. 23, 2022

Accepted: Feb. 02, 2022

\section{KEYWORDS}

Acetylcholinesterase inhibition,

Alzheimer's disease,

Rosmarinus officinalis,

Sideritis dichotoma, Pistacia terebinthus.

\section{INTRODUCTION}

Alzheimer's disease (AD) is a neurodegenerative disorder that shows memory loss as a primary symptom and increased incidences are observed in industrialized countries having elderly populations. Although the pathogenesis of AD could not be fully elucidated, the most clarified hypothesis is the lack of the acetylcholine (ACh) molecule, known as the cholinergic hypothesis(Cavdar et al., 2019). ACh molecule acts as a neurotransmitter in the synaptic gap and provides information flowing among neurons, so the cholinergic hypothesis is explained by the deficiency of acetylcholine and the loss of the cholinergic system (Adewusi et al., 2011). The predominant marker of cholinergic system deficiency can be an increased activity of

\footnotetext{
*CONTACT: Mehmet Emin DIKEN $\bigotimes$ mediken@balikesir.edu.tr Technology Application and Research Center, Balikesir, Turkiye
}

Balikesir University, Science and 
acetylcholinesterase (AChE) (EC 3.1.1.7), which degrades $\mathrm{ACh}$, and/or the inhibition of cholineacetyltransferase, which is involved in the synthesis of acetylcholine (Fu et al., 2004). The recovery of ACh can be carried out by inhibition of AChE with utilized inhibitors. Therefore, many AChE inhibition studies have been done to solve this problem. Many synthetic drugs are available on the market such as tacrine, donepezil, rivastigmine and galanthamine as AChE inhibitors (Yang etal., 2015; Cavdar et al., 2019;Dave et al., 2000). In fact, AChE inhibitors for $\mathrm{AD}$ treatment are the only group of drugs in which a certain success ratio is achieved, but their use have been limited due to their detrimental side effects (Colovic, et al., 2013).

Another reason for the progression of $\mathrm{AD}$ is oxidativestress that leads to neurotoxicity through the generation and spread of reactive oxygen species (ROS)(Zhao\& Zhao, 2013).Therefore, AD prevention or treatment with natural antioxidants should be considered as an alternative approach. Some medicinal plants are used as natural components of AChE inhibitors instead of synthetic drugs because of their prosperous antioxidant capacities. For example, huperzin $\mathrm{A}$ is a promising drug for treating $\mathrm{AD}$ symptoms with a very strong and reversible inhibitory effect on $\mathrm{AChE}$ and it is isolated from a plant, Lycopodium serratum (Thunb.) Trev. (Syn. Huperzia serrata Thunb.) (Ozarowski et al., 2017; Wang et al., 2006). In addition, there are more interesting results in the literature about the inhibitory effects of some other plant extracts like Salvia miltiorrhiza radix extracts which have stronger inhibitory capacities than huperzin A (Ozarowski et al., 2017). Some Salvia species were also reported as memory enhancers because of their monoterpene compositions that lead to strong and reversible anti-acetylcholinesterase activities both in vitro and in vivo (Bahadori et al., 2016; Perry et al., 2000). Another examples showing the advantage of strong antioxidant activities to deal with neurodegenerative diseases are Gingko biloba and Panax ginseng plants (Bastianetto et al., 2000; Chang et al., 2016).

In this study, Rosmarinus officinalis L (RO), Pistacia terebinthus L (PT) and Sideritis dichotoma Huter $(S D)$ plant samples with known chemical profiles were analyzed in detail for the AChE inhibition capacities. The results were compared with the previous findings in which some of the extracts in different concentrations were found as ineffective. In addition, the antioxidant properties were revealed by DPPH and ABTS radical scavenging methods, the phenolic contents were identified by Folin-Ciocalteu method and terpenes in these plant extracts were analyzed using gas chromatography coupled to mass spectrometry (GC-MS). The antimicrobial effects of the extracts against pathogenic bacteria were also analyzed in this study by disc diffusion method because it is known that the dysbiosis of microbes, which can occur because of the pathogenic bacteria invading the intestine, may lead to brain dysfunctions and $\mathrm{AD}$ may be associated with that (Angelucci et al., 2019). Considering the potential use of these plants for therapeutic purposes, it is also necessary to better understand the toxicities in living organisms. Therefore, in vivo toxicities of $R O, P T$ and $S D$ were analyzed in this study using Drosophila melanogaster as a model organism because of the many developmental mechanisms they share with mammals (Macedo et al., 2017).

\section{MATERIAL and METHODS}

\subsection{Materials}

Rosmarinus officinalis (RO), Pistacia terebinthus (PT) and Sideritis dichotoma (SD) were collected and identified by Prof. Dr. Serap DOĞAN at their ripening period in Balikesir, Turkey. The body, leaf, flower parts and fruits of the collected plants were powdered with a grinder mill after drying at room temperature in the dark. All chemicals were purchased from Sigma-Aldrich. 


\subsection{Methods}

\subsubsection{Preparation of Plant Extracts}

The powdered $R O, S D$ and $P T$ samples were prepared with $\mathrm{MeOH}, \mathrm{EtOH}$ and water solvents. A 0.5 g portion of powdered samples were dissolved in $5 \mathrm{~mL}$ solvent. It was kept in a fridge $\left(+4^{\circ} \mathrm{C}\right)$ overnight. Then, it was centrifugated for $10 \mathrm{~min}$ at $4000 \mathrm{rpm}$, and supernatant was removed. After the centrifugation, the pellets were rewashed with $5 \mathrm{~mL}$ and $2 \mathrm{~mL}$ of solvents. Then, the supernatants were combined. Solvents were removed by evaporation process. The residuals were stored at $-20{ }^{\circ} \mathrm{C}$ until analysis. Stock solutions of the extracts were prepared to use as $25 \mathrm{mg} \mathrm{mL}^{-1}$ for all analyzes.

\subsubsection{Preparation of Enzyme Extract}

$100 \mathrm{mg}$ of $D$. melanogaster larvae were homogenized by tissue homogenisator in $1 \mathrm{~mL}$ of 50 $\mathrm{mM}$ phosphate buffer ( $\mathrm{pH} 8.0$ ) containing $300 \mathrm{mM}$ sucrose. The homogenate was centrifuged at $4000 \mathrm{~g}$ for $4 \mathrm{~min}$ at $4{ }^{\circ} \mathrm{C}$. Supernatant was separated and used for experimental purposes (Assis et al., 2012).

\subsubsection{Enzyme Activity and Inhibition}

$\mathrm{AChE}$ enzyme reaction was measured spectrophotometrically by the formation of the yellow 5-thio-2-nitrobenzoate anion as a result of the reaction of thiocholines with DTNB. AChE activity and inhibition assays were performed according to the methods decribed by Ellman et al. (Ellman et al., 1961) and Senol et al. (Şenol et al., 2010).

In order to determine the enzyme activity, $150 \mu \mathrm{L}$ of $0.1 \mathrm{mM}$ phosphate buffer ( $\mathrm{pH} 8.0$ ), 20 $\mu \mathrm{L}$ of $10 \mathrm{mM}$ DTNB and $20 \mu \mathrm{L}$ of AChE solutions were combined in a 96-well microplate with a multi-channel automatic pipette, and then incubated at $37{ }^{\circ} \mathrm{C}$ for 15 minutes. After the incubation, the reaction was started with the addition of $10 \mu \mathrm{L}$ of $10 \mathrm{mM}$ acetylcholine iodide and monitored by a microplate reader at $412 \mathrm{~nm}$ (Şenol et al., 2010). The experiments were assayed in triplicate.

For inhibition assay, test mixtures $(200 \mu \mathrm{L}$ total volume) were prepared with $0.1 \mathrm{mM}$ phosphate buffer ( $\mathrm{pH} 8.0,120-155 \mu \mathrm{L}$ of $0.1 \mathrm{mM})$, substrate solutions (ACh and DTNB) at various concentrations prepared in buffer $(2.5-22.5 \mu \mathrm{L}$ of $10 \mathrm{mM})$, the inhibitor solution $(25 \mu \mathrm{g}$ $\mu \mathrm{L}^{-1}$ ) at fixed concentrations and $20 \mu \mathrm{L}$ enzymatic extract solutions. Blank (reference) sample contained all of the components except the enzyme extract with a final volume of $190 \mu \mathrm{L}$. The reaction was initiated by adding the substrate to the assay medium. The $\mathrm{IC}_{50}$ values were determined for all extracts in this way. The types of inhibition were determined using an extract of each plant sample with the best $\mathrm{IC}_{50}$ value. The inhibition kinetic analysis of $D$. melanogaster $\mathrm{AChE}$ was determined in the absence and in the presence of $R O-\mathrm{EtOH}, S D-\mathrm{EtOH}$, and $P T$ $\mathrm{MeOH}$ at two different concentrations. Inhibition constants ( $\mathrm{Ki}$ and $\mathrm{Ki}$ ') were concluded from the Lineweaver-Burk plots (Doğanet al., 2011).

\subsubsection{Determination of antioxidant capacities}

2.2.4.1. DPPH radical scavenging activity. The antioxidant capacities of $R O, S D$ and $P T$ were determined using 1,1-diphenyl-2- picrylhydrazyl (DPPH) radical scavenging activity (Blois, 1958). A $0.024 \mathrm{~g}$ portion of DPPH was dissolved in $100 \mathrm{~mL} \mathrm{MeOH}$. Then, $0.05 \mathrm{~mL}$ of plant extract, $2.5 \mathrm{~mL}$ of DPPH solution and $2.5 \mathrm{~mL}$ of $\mathrm{MeOH}$ were added into a test tube and were kept in the dark for $1 \mathrm{~h}$. For the control, $\mathrm{MeOH}$ was used instead of a sample. Spectrophotometric measurements were done at $517 \mathrm{~nm}$. The radical scavenging activity of the samples were calculated using the following formula;

\section{Antioxidant Activity (\%) $=[1-($ absorbance of sample / absorbance of control) $] \times 100$}


2.2.4.2. ABTS radical scavenging activity. ABTS radical scavenging activity of the samples were performed by the method of Re et al. (Re et al., 1999). ABTS ${ }^{+}$radical solution was prepared using equal volumesof $7 \mathrm{mM}$ ABTS salt and $2.4 \mathrm{mM}$ ammonium persulphate and kept in dark overnight. After then, the solution was diluted with $\mathrm{MeOH}$ until an absorbance of $1.50 \pm 0.01$ at $734 \mathrm{~nm}$ was obtained. This absorbance was recorded as a control. For the sample analysis, $2.95 \mathrm{~mL}$ of the $\mathrm{ABTS}^{+}$solution and $0.05 \mathrm{~mL}$ of sample (extract) were added in a 3 $\mathrm{mL}$ cuvette. Measurements were done at $734 \mathrm{~nm}$ by a UV-Visible spectrophotometer (Perkin Elmer lambda-35 UV-Visible spectrophotometer). The measurements were performed in triplicate for each extract. ABTS radical scavenging activity (\%) of the extracts were calculated with the following formula;

\section{Antioxidant Activity (\%) = [1-(absorbance of sample / absorbance of control) $]$ x 100}

\subsubsection{Determination of total phenolic content}

The phenolic contents of $R O, S D$ and $P T$ were analyzed by the Folin-Ciocalteu method (Dogan et al., 2010). A $3.5 \mathrm{~mL}$ portion of distilled water, $0.25 \mathrm{~mL}$ Folin reagent, and $0.25 \mathrm{~mL}$ of extract were combined in a test tube and incubated in the dark for $3 \mathrm{~min}$ at room temperature. $\mathrm{NaCO}_{3}$ was added to the test tube $(1 \mathrm{~mL}$ of $20 \%)$ and incubated for $40 \mathrm{~min}$ at $40{ }^{\circ} \mathrm{C}$. For the control sample, $\mathrm{MeOH}$ was used instead of the plant extract. After the $40 \mathrm{~min}$, absorbance values of all samples were measured at 685 nmby UV-Visible spectrophotometer. Total phenolic compounds were identified using the gallic acid calibration curve, and the results were calculated as $\mu \mathrm{g}$ gallic acid/g.

\subsubsection{GC-MS analysis for the composition of terpene derivatives}

The composition of the plant extracts' terpene derivatives were performed by capillary GC/MS using Shimadzu 6890N Network GC-2010 plus system combined with Shimadzu GC/MSQP2010 ultra mass spectrometerdetector.

In order to perform GC analysis $30 \mathrm{~m} \times 0.25 \mathrm{~mm} \times 0.25 \mu \mathrm{m}$ HP Innowax Capillary column was used. The oven program was adjusted to keep the column'sinitial temperature at $60{ }^{\circ} \mathrm{C}$ for $10 \mathrm{~min}$ after injection, rise to $220^{\circ} \mathrm{C}$ with $4{ }^{\circ} \mathrm{C} / \mathrm{min}$ heating ramp for $10 \mathrm{~min}$ and increase to $240{ }^{\circ} \mathrm{C}$ with $1{ }^{\circ} \mathrm{C} / \mathrm{min}$ heating ramp. The injector temperature was adjusted to $250{ }^{\circ} \mathrm{C}$, carrier gas was helium, in let pressure was $20.96 \mathrm{psi}$, linear gas velocity was $28 \mathrm{~cm} / \mathrm{s}$, column flow was $1.2 \mathrm{~mL} / \mathrm{min}$, the split ratio was $40: 1$ and injection volume was $1.0 \mu \mathrm{L}$.

MS conditions were adjusted as follows; ionization energy:70 eV; ionsource temperature: $280^{\circ} \mathrm{C}$; integral temperature: $250^{\circ} \mathrm{C}$; and mass range: $34-450$ atomic mass units. Identification of the terpenes in the $R O, P T$ and $S D$ were determined by comparison of their mass spectra and retention times with the GC/MS Wiley and Nist Mass Spectral Searchlibrary. The proportion of the compounds were calculated from the GC peak areas by the normalization method.

\subsubsection{Disc diffusion method for antibacterial activity}

The bacteria were maintained on Muller-Hinton agar (MHA). Two bacteria strains were selected, including the Gram-positive bacteria Staphylococcus aureus (ATCC 6538) and the Gram-negative bacteria Escherichia coli (ATCC 8739). Antibacterial activities of the samples were evaluated using the paper disc agar diffusion method defined by National Committee for Clinical Laboratory Standard. The paper discs $(6 \mathrm{~mm}$ diameter) were incubated with the extracts overnight. After, the impregnated discs were placed on petri dishes inoculated with bacteria strains $\left(10^{5} \mathrm{CFU} / \mathrm{mL}\right)$. The petri dishes were incubated at $37^{\circ} \mathrm{C}$ for $24 \mathrm{~h}$. Finally, the diameters of the inhibition zones forming around the discs were measured to evaluate antibacterial activities of the extracts. 


\subsubsection{In vivo toxicological analyses}

2.2.8.1. Fly rearing conditions of Drosophila melanogaster strains. The standard growth medium was prepared by dissolving sugar (43 g), agar ( 9 gr), semolina (90 gr), yeast ( $25 \mathrm{gr})$, antifungal drug (200 $\mu$, Mikostatin-Deva Holding-228/97) and propionic acid (5 ml) in $500 \mathrm{ml}$ of water (Chung et al., 2009; Yakovleva et al., 2016). $25 \mathrm{~g}$ of media was then proportioned into sterile glass cultures vials and the flies were kept in glass bottles at $22{ }^{\circ} \mathrm{C}$.

2.2.8.2. The larval (eclosion) assay. The assay was performed according to Liu et al. with minor modifications (Liu et al., 2015). All of the D. melanogaster flies used in this study were Oregon $\mathrm{R}$ wild-type strains. 25 adult male and female $D$. melanogaster flies were placed into cultures bottles. After $48 \pm 4$ hours of incubation, $1^{\text {st }}$ instar larvae were collected and rinsed with distilled water. Plant extracts $(25 \mathrm{mg} / \mathrm{L})$ and $\mathrm{H}_{2} \mathrm{O}_{2}(6.5 \mu \mathrm{g} / \mathrm{mL})$ were directly applied to the growth media. The negative control was prepared without any treatment and the positive control was prepared by adding $\mathrm{H}_{2} \mathrm{O}_{2}(6.5 \mu \mathrm{g} / \mathrm{mL})$. Equal numbers of $1^{\text {st }}$ instar larvae were added into the experimental bottles and then incubated at $22{ }^{\circ} \mathrm{C}$ until they became adults. The pupae and eclosed adult fly numbers were counted (Liu et al., 2015). The puparation \%, survival rate $\%$ and eclosion \% were calculated according to the previous studies (Depetris-Chauvin et al., 2017; Liu et al., 2015; Macedo et al., 2017; Rand et al., 2014; Riaz et al., 2018) using the following formulas;

$$
\begin{aligned}
& \text { Puparation } \%=\frac{\text { Numberofpupae }}{\text { Numberoflarvae }} \times 100 \\
& \text { Survival rate }(\%)=\frac{\text { Numberofadultflies }}{\text { Numberoflarvae }} \times 100 \\
& \text { Eclosion } \%=\frac{\text { Numberofadultflies }}{\text { Numberofpupae }} \times 100
\end{aligned}
$$

\subsubsection{Statistical analysis}

The standard error (SE) was calculated using three biological repeats, paired student $t$ test was used and $p<0.05$ was determined as statistically significant for in vivo toxicological analyses. Other findings were presented as mean \pm standard deviation $(\bar{X} \pm s)$ of three biological repeats by Anova Test. All of the calculations and statistics of this study were performed by Microsoft Office Excel.

\section{RESULTS}

\subsection{Enzyme Activity and Inhibition Results}

The kinetic constants of the AChE enzyme obtained from D. melanogaster were presented in Table 1. They were calculated from Lineweaver-Burk equation using the acetylcholine substrate. The Michaelis constant $(\mathrm{Km})$ and maximum reaction velocity (Vmax) values were calculated from the Lineweaver-Burk double reciprocal plots and values for the acetylcholine substrate were calculated as $1.94 \mathrm{mM}$ and $17.95 \mathrm{EU} / \mathrm{mL}$ min, respectively.

Table 1. Kinetic values of AChE of Drosophila melanogaster.

\begin{tabular}{lccc}
\hline Substrate & $\mathrm{Km}(\mathrm{mM})$ & $\mathrm{Vmax}(\mathrm{EU} / \mathrm{mL} \min )$ & $\mathrm{Vmax} / \mathrm{Km}(\mathrm{EU} / \mathrm{mL} \mathrm{min} \mathrm{mM})$ \\
\hline Acetycholine iodide & 1.94 & 17.95 & 9.26 \\
\hline
\end{tabular}

It is well known that most of the medicinal plants possess antioxidant activities. This property makes them very effective protectors against various diseases and memory deficits, in addition to their capacity of reducing the toxicities of toxic agents or other drugs (Karimi et al., 
2015). $R O, P T$ and $S D$ are the plants used to treat many diseases by local people. However, there was not enough data in the literature about their inhibition capacities on AChE that would make them natural alternatives of synthetic drugs without detrimental side effects leading to serious disorders in human metabolism (Colovic et al., 2013). Therefore, this study aimed to analyse the AChE inhibition types and capacities of $R O, P T$ and $S D$ extracts prepared with $\mathrm{EtOH}, \mathrm{MeOH}$ and water. The enzyme inhibition assay results were given in Table 2, Table 3 and at Figure 1.

Table 2. $\mathrm{IC}_{50}$ values of the plant samples on AChE of Drosophila melanogaster.

\begin{tabular}{lccc}
\hline & \multicolumn{3}{c}{$\mathrm{IC}_{50}(\mu \mathrm{g} / \mu \mathrm{L})$} \\
\cline { 2 - 4 } Samples & MeOH extract & EtOH extract & Aqueous extract \\
\hline$P T$ & $0.86 \pm 0.05$ & $2.54 \pm 0.11$ & $4.76 \pm 0.24$ \\
$S D$ & $2.19 \pm 0.15$ & $2.01 \pm 0.08$ & $2.54 \pm 0.14$ \\
$R O$ & $1.21 \pm 0.07$ & $0.57 \pm 0.02$ & $1.98 \pm 0.13$ \\
\hline
\end{tabular}

Galanthamine (reference) $0.09 \mu \mathrm{g} / \mu \mathrm{L}$.

According to Table 2, it was determined that extracts of $R O$ had highest inhibitory activity among all of the plants, and its $\mathrm{EtOH}$-extract showed the best inhibition activity with an $\mathrm{IC}_{50}$ value of $0.57 \pm 0.02 \mu \mathrm{g} / \mu \mathrm{L}$, followed by the $\mathrm{MeOH}$ and water extracts with $\mathrm{IC}_{50}$ values of $1.21 \pm 0.07$ and $1.98 \pm 0.13 \mu \mathrm{g} / \mu \mathrm{L}$, respectively. Previously, Ozarowski et al. reported a study with $R O$ L. leaf extract against AChE activity (Ozarowski et al., 2013). They found that leaf extract prepared with $50 \% \mathrm{EtOH}$ showed long-term inhibitory effect on AChE in rat's brain and they suggested that the $R O$ leaf may be a possible option to prevent some neurodegenerative diseases (Ozarowski et al., 2013). Our results were consistent with those findings. However, in another study, Orhan et al. reported that different extracts of $R O$ prepared with methanol, petroleum ether, chloroform and ethyl acetate solvents were ineffective on AChE activity at 0.2 and $0.5 \mu \mathrm{g} / \mu \mathrm{L}$ concentrations (Orhan et al., 2008). However, in this study $25 \mu \mathrm{g} / \mu \mathrm{L}$ of $R O$ extracts were used and strong inhibition was observed, so the difference between our results and Orhan et al. (Orhan et al., 2008) may be occurred due to the differences of the doses.

According to the results given in Table 2, the extracts of $P T$ also exhibited an effective inhibitory potential against $\mathrm{AChE}$. The $\mathrm{MeOH}$-extracts of $P T$ exhibited the best inhibition potential $\left(\mathrm{IC}_{50}=0.86 \pm 0.05 \mu \mathrm{g} / \mu \mathrm{L}\right)$, followed by EtOH-extract $\left(\mathrm{IC}_{50}=2.54 \pm 0.11 \mu \mathrm{g} / \mu \mathrm{L}\right)$ and water extract $\left(\mathrm{IC}_{50}=4.76 \pm 0.24 \mu \mathrm{g} / \mu \mathrm{L}\right)$. The information in the literature is limited to compare with our data, but there is a study about the effect of $P T$ extracts prepared with ethyl acetate and methanol on AChE activity (Orhan Erdogan et al., 2012). Researchers found that the PT extracts $(25,50,100$, and $200 \mu \mathrm{g} / \mathrm{mL})$ did not show inhibitions against AChE but they selectively inhibited butyrylcholinesterase $(\mathrm{BChE})$ activity at the tested concentrations (Orhan Erdogan et al., 2012). In fact, it is an expected result to have different inhibition potentials at lower concentrations.

Table 3. Inhibition types and Ki values of Drosophila melanogaster AChE.

\begin{tabular}{lcccc}
\hline Inhibitors & $\mathrm{I}(\mu \mathrm{g} / \mu \mathrm{L})$ & $\mathrm{Ki}(\mu \mathrm{g} / \mu \mathrm{L})$ & $\mathrm{Ki}(\mu \mathrm{g} / \mu \mathrm{L})$ & $\begin{array}{c}\text { Type of } \\
\text { inhibition }\end{array}$ \\
\hline \multirow{2}{*}{$R O$ (EtOH-extract) } & 1.28 & --- & 1.47 & Uncompetitive \\
\hline \multirow{2}{*}{$S D$ (EtOH-extract) } & 1.88 & --- & 0.80 & Competitive \\
\hline \multirow{2}{*}{$P T(\mathrm{MeOH}-\mathrm{-} x \operatorname{coct})$} & 0.57 & 1.14 & --- & Competitive \\
\hline
\end{tabular}


$S D$ is a herbal tea consumed by local people because of its anti-inflammatory, antirheumatic, digestive and antimicrobial activities (Wang et al., 2006; Bahadori et al., 2016). In our study, all of the extracts of $S D$ effectively reduced the AChE activity. EtOH-extract of $S D$ showed the best inhibition activity against to $\mathrm{AChE}$ enzyme, and its $\mathrm{IC}_{50}$ value was found as $2.01 \pm 0.08 \mu \mathrm{g} / \mu \mathrm{L}$. $\mathrm{IC}_{50}$ values of $\mathrm{MeOH}$ and water extracts of $S D$ were also determined as $2.19 \pm 0.25$ and $2.54 \pm 0.14 \mu \mathrm{g} / \mu \mathrm{L}$, respectively. However, there isn't any research in the literature about the effects of $S D$ on cholinergic system enzymes.

In addition, one of the results that make our study different from the literature is the determination of the inhibition types seen in Figure 1.Lower $\mathrm{IC}_{50}$ values result from the higher inhibition of $\mathrm{AChE}$. Therefore, extracts with the lowest $\mathrm{IC}_{50}$ values were used to determine the inhibition types of each plant sample. Figure 1 shows the effects of $P T-\mathrm{MeOH}, R O-\mathrm{EtOH}$, and $S D$-EtOH inhibitors on D. melanogaster AChE using $\mathrm{ACh}$ as substrates. According to the results given in Figure 1(a), inhibition type of $R O$ was determined as uncompetitive. Uncompetitive inhibition occurs when an inhibitor binds only to the complex formed between the enzyme and the substrate (ES complex). On the other hand, the competitive inhibitions were observed in the reactions between the $P T$ and $S D$ inhibitors and substrate catalysed by AChE enzyme (Figure 1(b), (c)). Moreover, $\mathrm{Ki}$ and Ki' values for inhibitors used are shown in Table 3. The inhibition constants given for the plant extracts (inhibitors) were obtained by fitting the experimental data with Lineweaver-Burk equation for competitive and uncompetitive inhibition. As a result, from $\mathrm{Ki}$ values in Table 3, it can be said that $R O$ is a more effective inhibitor among the others due to lower $\mathrm{Ki}$ values. $S D$ and $P T$, respectively, follow the inhibition efficiency.

Figure 1. Inhibition types of $R O$-EtOH (a), $S D$-EtOH (b) and $P T$-MeOH (c) extracts on AChE enzyme of Drosophila melanogaster.

(a)

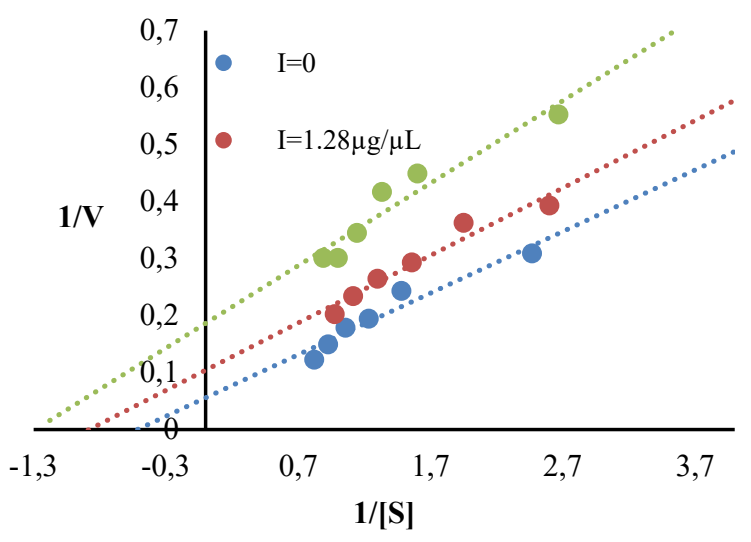

(b)

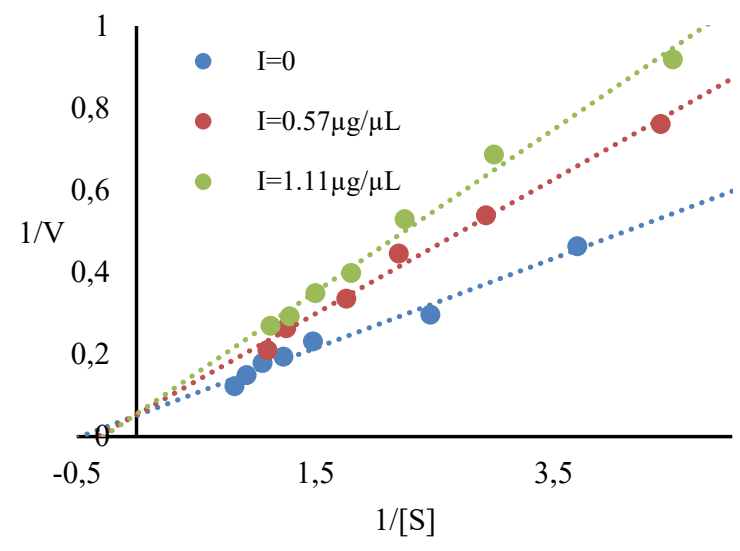

(c)

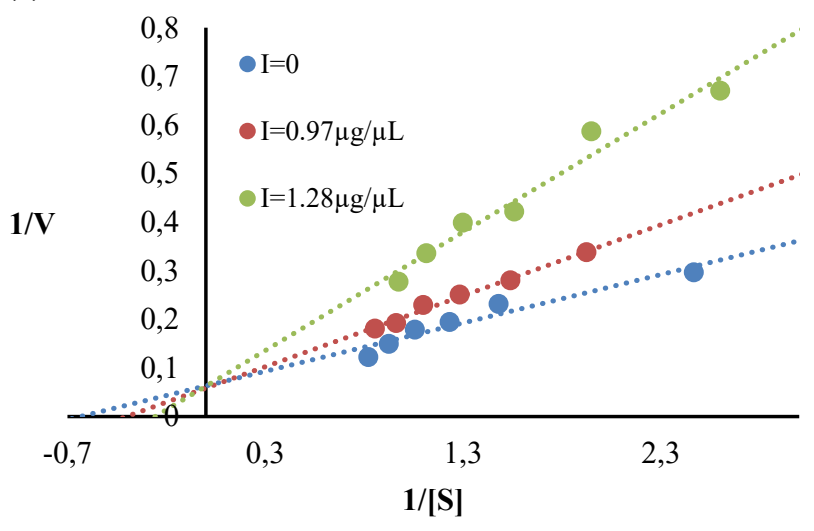




\subsection{Antioxidant capacity test results}

It is known that oxidative stress has important roles both in early stages and the development of AD by activating multiple cell signalling pathways that contribute dangerous lesions (Feng $\&$ Wang, 2012). Thus, antioxidant therapies are considered an alternative or supplementary therapy option for AD (Feng \& Wang, 2012). In fact, a great number of studies have examined the positive benefits of antioxidants to reduce or block neuronal death occurring in the pathophysiology of neurodegeneretive disorders like AD (Ramassamy, 2006).

In this study, DPPH and ABTS methods were used to determine the antioxidant properties of the plant extracts. According to the results, all extracts of $R O$ and $S D$ showed DPPH and ABTS radical scavenging activities equal or more than $90 \%$ (Table 4). Thus, it was obvious that the solvent types studied did not affect their antioxidant properties so their AChE inhibition capacities were not only dependent on their great antioxidant properties but also dependent on some unknown enzyme-specific inhibition mechanisms. Although DPPH and ABTS radical scavenging activities in EtOH-extract of $P T$ were less than $90 \%$ (Table 4), they were quite high in $\mathrm{MeOH}$-extract of $P T(96.94 \pm 1.84$ and $98.01 \pm 2.10 \%$, respectively). These results were consistent with our findings showing that AChE inhibition capacity (Table 2) and natural anticholinesterase compositions (Table 5) were high in $\mathrm{MeOH}$-extract of $P T$. In literature, researchers also have mentioned that $P T$ extracts might provide neuro-protection to some extent with their strong antioxidant effects by metal-chelation (Orhan et al., 2012).

Table 4. Antioxidant scavenging activity and total phenolic content of the extracts.

\begin{tabular}{|c|c|c|c|c|c|c|c|c|c|}
\hline \multirow[b]{2}{*}{ Sample } & \multicolumn{3}{|c|}{ DPPH Scavenging Activity (\%) } & \multicolumn{3}{|c|}{ ABTS Scavenging Activity (\%) } & \multicolumn{3}{|c|}{ Total Phenolic Content (g/100g) } \\
\hline & $\begin{array}{l}\mathrm{MeOH} \\
\text { extract }\end{array}$ & $\begin{array}{c}\text { EtOH } \\
\text { extract }\end{array}$ & $\begin{array}{r}\text { Aqu } \\
\text { ext }\end{array}$ & $\begin{array}{l}\mathrm{MeOH} \\
\text { extract }\end{array}$ & $\begin{array}{c}\text { EtOH } \\
\text { extract }\end{array}$ & us & $\begin{array}{l}\mathrm{MeOH} \\
\text { extract }\end{array}$ & $\begin{array}{l}\text { EtOH } \\
\text { extract }\end{array}$ & $\begin{array}{l}\text { cus } \\
\text { ct }\end{array}$ \\
\hline$T$ & & & & & & & & & \\
\hline$S D$ & & & & & & & 1.74 & & \\
\hline$O$ & $94.93 \pm 1.90$ & $95.15 \pm 2.1$ & $90.51 \pm 1.1$ & $97.90 \pm 2.1$ & $96.4 \pm 2.03$ & $97.04 \pm 1.66$ & $2.17 \pm 0$ & 55 & $1.86 \pm 0.05$ \\
\hline
\end{tabular}

\subsection{Total phenolic content results}

It is well known that there is a linear correlation between total phenolic content values and antioxidant capacities (Johari \& Khong, 2019). The total phenolic contents of all extracts of $R O, S D$ and $P T$ were determined in this study and expressed as g equivalent of gallic acid in $100 \mathrm{~g}$ of extract. According to the findings given in Table 4, MeOH-extract of $R O$ had the highest concentration of phenolic content $(2.17 \pm 0.05 \mathrm{~g} / 100 \mathrm{~g})$ among all extracts. It was followed by $S D$ water extract as $2.05 \pm 0.05 \mathrm{~g} / 100 \mathrm{~g}$ and $\mathrm{EtOH}$-extract of $P T$ as $1.63 \pm 0.03 \mathrm{~g} / 100 \mathrm{~g}$. The other extracts results were detected between $1.31 \pm 0.03$ and $1.86 \pm 0.05 \mathrm{~g} / 100 \mathrm{~g}$.

\subsection{GC-MS results}

Terpenes, the largest single class of compounds found in essential oils, have been shown to provide relevant protection under oxidative stress conditions like neurodegenerative disorders due to their antioxidant behaviors (Gonzalez-Burgos \& Gomez-Serranillos, 2012). Therefore, to be able to identify the terpene compositions (monoterpenes, diterpenes and sesquiterpenes) of the plants that showed AChE inhibition, GC/MS analyses were performed. When the antioxidant effects were compared with respect to solvents (Table 4), it was clearly seen that $\mathrm{MeOH}$-extracts of $P T$ and $S D$ showed the highest antioxidant capacities (above 95\%) and the same extract of $R O$ showed the highest phenolic content $(2.17 \pm 0.05 \mathrm{~g})$ which is also related to the antioxidant capacity. Therefore, $\mathrm{MeOH}$-extracts were chosen in GC/MS analyses. 
As seen in Table 5, twenty derivatives of terpenes were observed in $R O$ extracts and among these compounds some monoterpenes like limonene $(8.41 \%)$, borneol $(7.49 \%)$, verbenone $(6.19 \%)$ and camphor $(4.68 \%)$ were at high concentrations. It was also clearly seen that acetylcholinesterase inhibitors such as 1,8-cineole, $\alpha$-pinene, limonene, borneol, terpinene and verbenone, which are monoterpenes, were found in $R O$ extracts. These results were consistent with the high AChE inhibition effects of $R O$ extracts observed in this study.

Table 5. Composition of some terpene derivatives in $R O, P T$ and $S D$ extracts.

\begin{tabular}{lccc}
\hline \multicolumn{1}{c}{ Compounds } & $\begin{array}{c}R O \\
\text { (Area \%) }\end{array}$ & $\begin{array}{c}P T \\
\text { (Area \%) }\end{array}$ & $\begin{array}{c}S D \\
\text { (Area \%) }\end{array}$ \\
\hline 1,8-cineole & 0.77 & 0.19 & 1.60 \\
$\alpha$-pinen & 0.01 & 0.09 & 0.001 \\
Camphor & 4.68 & 0.41 & 2.11 \\
Borneol & 7.49 & 0.51 & 1.19 \\
Terpinene & 0.12 & 0.28 & 0.09 \\
-terpineol & 0.01 & 0.39 & 1.24 \\
Verbenone & 6.19 & 0.11 & ND \\
Carvacrol & 0.46 & 12.19 & 7.84 \\
Viridiflorol & 0.19 & 1.15 & 1.59 \\
Caryophyllene & 0.04 & $\mathrm{ND}$ & 0.33 \\
Terpinolene & $\mathrm{ND}$ & 0.43 & 0.67 \\
Manool & $\mathrm{ND}$ & $\mathrm{ND}$ & 1.72 \\
Thymol & 0.50 & 12.78 & 8.78 \\
Limonene & 8.41 & 0.01 & $\mathrm{ND}$ \\
Linalool oxide & 0.004 & $\mathrm{ND}$ & $\mathrm{ND}$ \\
Linalool & 0.013 & 0.03 & 0.02 \\
Phytol & 0.006 & 4.06 & 0.02 \\
Dihydrocarveol & 0.005 & $\mathrm{ND}$ & $\mathrm{ND}$ \\
Totarol & 1.61 & $\mathrm{ND}$ & 2.59 \\
\hline ND: & & & \\
\hline
\end{tabular}

ND: non-detected

According to our GC/MS results with PT extracts (Table 5), thymol (12.78\%) and carvacrol $(12.19 \%)$ were found as main terpenes, followed by phytol $(4.06 \%)$. It was also observed that $P T$ extracts have many monoterpenes such as camphor, borneol, viridiflorol, $\alpha$-terpineol, $\alpha-$ pinene and 1,8-cineole are natural anti-cholinesterase molecules (especially against to AChE) (Dave et al., 2000; Ozarowski et al., 2017). Thus, the GC/MS results of $P T$ were consistent with our findings with AChE inhibition data.

GC/MS results showed that monoterpenes were predominant among numerous derivatives of terpenes in $S D$ extracts. Among the compounds, thymol and carvacrol were found highest concentrations as 8.78 and $7.84 \%$, respectively. Moreover, many monoterpenes such as totarol, camphor, manool, 1,8-cineole, borneol, $\alpha$-terpineol and viridiflorol were determined in high concentration, too. The total concentration of terpene derivatives observed in $S D$ extracts were approximately $30 \%$ of the extract and this can explain the strong inhibition activity of $S D$ extracts observed in this study.

\subsection{Antibacterial activity results}

Antibacterial characteristic and the antioxidant activity of plant extracts are one of the most studied features for control of human and animal diseases of bacterial origin (Zhang et al., 2016). In addition, there is a hypothesis about the pathogenic bacteria invading the intestine can lead to brain dysfunctions by changing the flora of the intestine and AD may be associated with 
that (Angelucci et al., 2019). Therefore, the antibacterial effect of $R O, P T$ and $S D$ extracts were investigated in this study by disc diffusion method. According to the results given in Table 6 and Figure 2, all extracts showed antibacterial effects with obvious inhibition zones. However, the strongest antibacterial activity against $S$. aureus was found with the EtOH-extract of $R O$ (25.77 mm inhibition zone) and the one against $E$. coli was found with the EtOH-extract of $S D$ (19.52 mm inhibition zone). When the solvent types were compared, EtOH-extracts were found as more effective against $S$. aureus and E. coli than other extracts. Previous studies related to the different extracts of $R O, P T$ and $S D$ showed different antibacterial activity values (Bozin et al., 2007; Dhifi et al., 2012; Durak \& Uçak, 2015; Fernández-López et al., 2005; Kilic et al., 2003). Compared with the literature values, the results of this study showed higher activities against $S$. aureus and E. coli than most of the others. All of the plants studied here can be regarded as natural antibiotics because they showed strong activities against both gram-positive and gram-negative bacteria. Therefore, $R O, P T$ and $S D$ should be considered as potential candidates for $\mathrm{AD}$ pharmaceutical applications with their important capacities to reduce $\mathrm{AChE}$ activity, their important phytochemical ingredients, and their prevention capacities from pathogenic bacteria.

Figure 2. Antibacterial activity results of the plants extracted in solvents against $S$. aureus and E. Coli performed by disc diffusion method (a- EtOH-extracts, c- $\mathrm{MeOH}$-extracts, e- water-extracts against to $S$. aureus and b- EtOH-extracts, d- $\mathrm{MeOH}$-extracts, f- Water-extracts against to E. coli) (C-Positive Control (Ampiciline), RO-Rosmarinus officinalis, SD-Sideritis dichotoma, PT-Pistacia terebinthus).

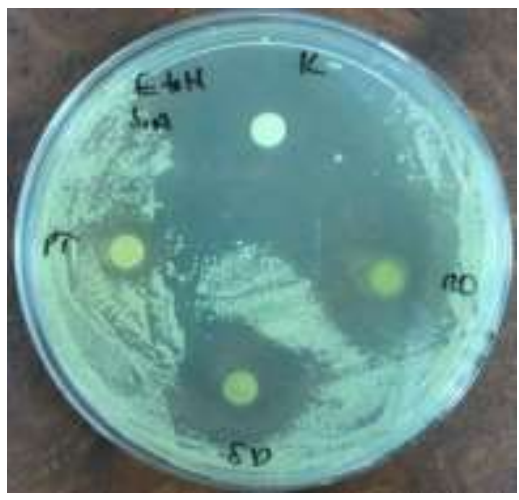

(a)

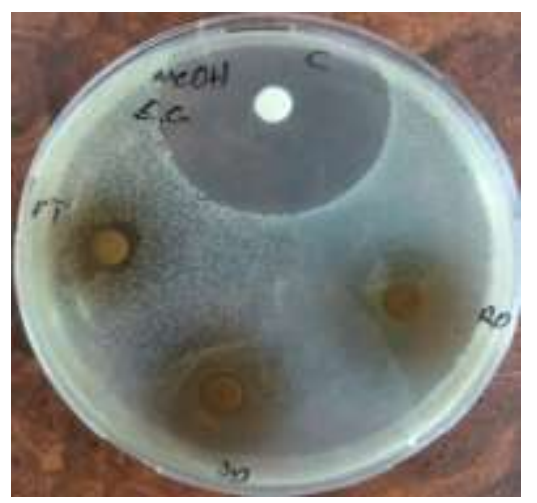

(d)

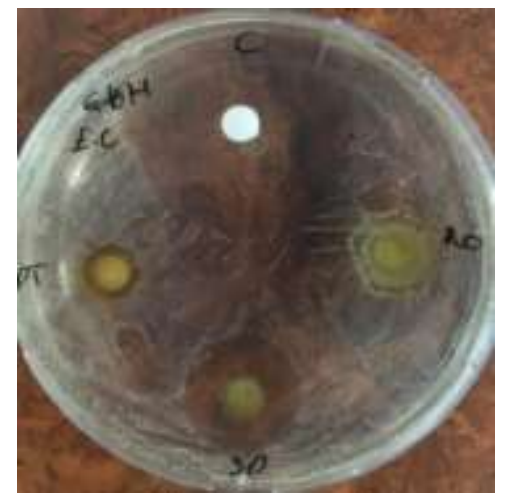

(b)



(e)



(c)

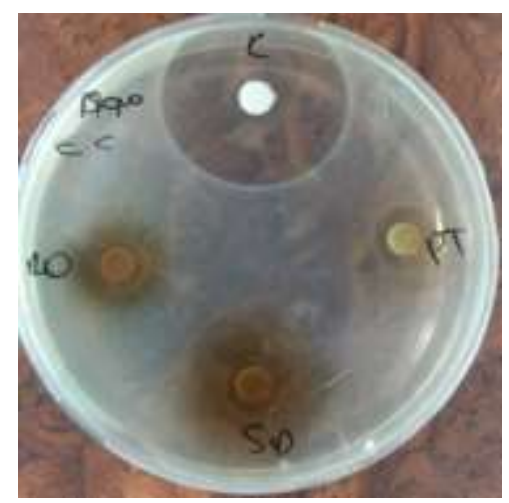

(f) 
Table 6. Antibacterial activity results of the extracts against $S$. aureus and E. coli bacteria.

\begin{tabular}{lcccccc}
\hline & \multicolumn{5}{c}{ Inhibition zone diameter (mm) } \\
\cline { 2 - 7 } Samples & \multicolumn{2}{c}{ MeOH extract } & \multicolumn{2}{c}{ EtOH extract } & \multicolumn{2}{c}{ Aqueous extract } \\
\cline { 2 - 7 } & E. coli & S. aureus & E. coli & S. aureus & E. coli & S. aureus \\
\hline$P T$ & 11.54 & 10.32 & 9.07 & 11.22 & 10.38 & 9.03 \\
$S D$ & 15.08 & 13.94 & 19.52 & 20.58 & 11.60 & 11.92 \\
$R O$ & 12.04 & 15.03 & 12.69 & 25.77 & 12.14 & 13.84 \\
Control (Ampicilin) & 28.96 & 24.22 & 33.39 & 34.97 & 26.42 & 23.02 \\
\hline
\end{tabular}

\subsection{Results of in vivo toxicological analyses}

The larval (eclosion) assays are recent techniques used to screen the effects of developmental susceptibility or tolerance to toxicants in vivo (Rand et al., 2014). The assay is based on the relationship between toxic compounds and the metamorphosis process of Drossophila which is regulated by activation of four hormones (ecdysis triggering hormone, eclosion hormone, crustacean cardioactive peptid and bursicon) (Macedo et al., 2017). In order to determine the toxicologic effects of $R O, P T$ and $S D$ extracts in vivo, the larval (eclosion) assay was performed in this study and the results were given in Figure 3. The extracts that showed highest AChE inhibition values in this study (EtOH extract of $R O, \mathrm{MeOH}$ extract of $P T$ and EtOH extract of $S D)$ were analyzed in this assay. According to the results, it was clearly seen that $\mathrm{H}_{2} \mathrm{O}_{2}$ caused significant decreases $(p<0.05)$ in puparation \%, survival rate \% and eclosion \% (Figure 3(a), (b), (c)). However, when the $R O, P T$ and $S D$ extracts were applied there was no significant change in puparation $\%$, survival rate $\%$ or eclosion \% (Figure 3(a), (b), (c)). In addition, extracts co-administered with $\mathrm{H}_{2} \mathrm{O}_{2}\left(R O+\mathrm{H}_{2} \mathrm{O}_{2}, P T+\mathrm{H}_{2} \mathrm{O}_{2}\right.$ and $\left.S D+\mathrm{H}_{2} \mathrm{O}_{2}\right)$ showed similar puparation and eclosion \% values like negative control (Figure 3(a), (c)). Although there is a decrease in survival rate (\%) of cultures treated with $P T+\mathrm{H}_{2} \mathrm{O}_{2}$, the value was significantly higher than the ones treated with $\mathrm{H}_{2} \mathrm{O}_{2}$ alone $(p<0.05)$. Therefore, it can be concluded that none of the extracts used in this study was toxic for Drossophila and they ameliorated the $\mathrm{H}_{2} \mathrm{O}_{2}$ induced decrease of puparation $\%$, survival rate $\%$ and eclosion $\%$ values. To date, no study has demonstrated the developmental susceptibility or tolerance to $R O, P T$ and $S D$ extracts in vivo. However, there are some studies in literature about in vivo toxicological effects of different plant species on Drosophila (Liu et al., 2015; Macedo et al., 2017; Riaz et al., 2018). For example, Liu et al. studied the effects of Coriandrum sativum, Nardostachys jatamansi, Polygonum multiflorum, Rehmannia glutinosa and Sorbus commixta on Drosophila strains and found significant increases in survival rate \% with those plant extracts compared to the ones with AD phenotypes (Liu et al., 2015). In another study, it was investigated that hydroalcoholic extract from leaves of Senecio brasilienis (Spreng) Less. caused significant decrease in the eclosion rate of flies at higher concentrations $(1 \mathrm{mg} / \mathrm{ml}$ ) (Macedo et al., 2017). The toxicity of petroleum extract of Euphorbia prostrata, Parthenium hysterophorus, Fumaria indica, Chenopodium murale and Azadirachta indica against D. melanogaster were also studied (Riaz et al., 2018). According to Riaz et al., E. prostrata was the only one with high mortality $(51.64 \%)$ at $30 \%$ concentration and it was significantly higher than the negative control after $72 \mathrm{~h}$ of incubation. 
Figure 3. EtOH extract of $R$. officinalis $(R O), \mathrm{MeOH}$ extract of $P$. terebinthus $(P T)$ and EtOH extract of $S$. dichotoma $(S D)$ extracts ameliorated the decreased a-puparation $\%$, b-survivalrate $(\%)$ and ceclosion \% of Drosophila. * indicates that $p<0.05$ compared to negative control.

(a)

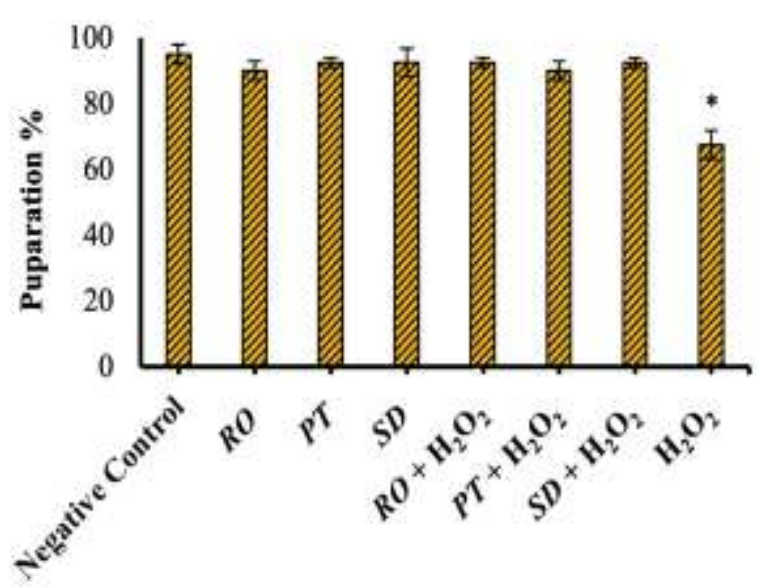

(b)

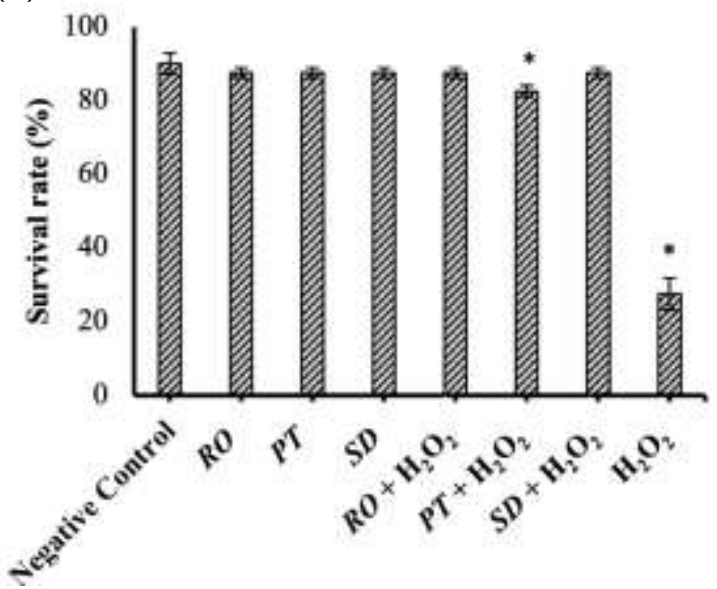

(c)

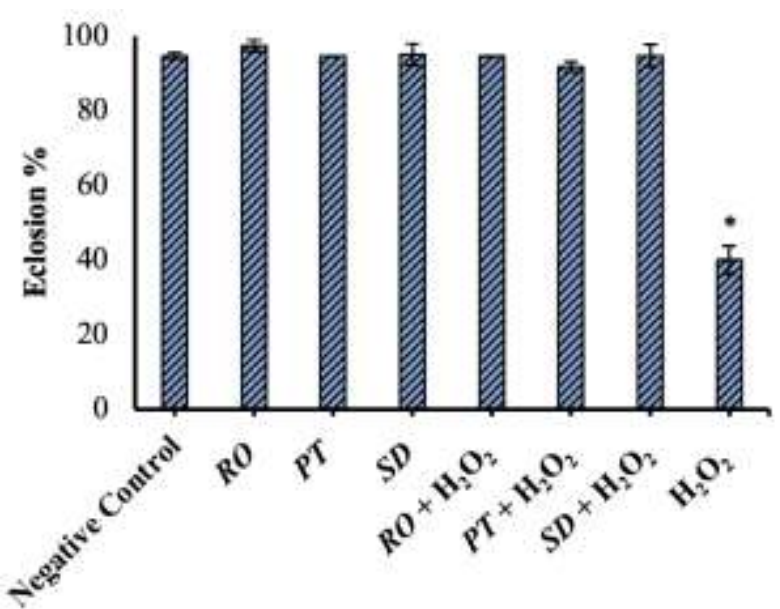

\section{DISCUSSION and CONCLUSION}

Although the pathogenesis of AD has not been fully deciphered yet, increased activity of AChE and oxidative stress are considered the main reasons for (Cavdar et al., 2019; Zhao \& Zhao, 2013). Natural compounds have become an emerging and promising area of research for the therapy of neurodegenerative diseases like AD because of their strong antioxidant capacities (Ramassamy, 2006). Therefore, this study identified the inhibition capacities of $R O, P T$ and $S D$ extracts on AChE, the antioxidant properties, phenolic contents, terpene compositions, antibacterial effects, and in vivo toxicities of the plants. All of the plant extracts showed strong inhibitory effects on AChE activity. The inhibition type of $R O$ was uncompetitive, while $S D$ and $P T$ extracts showed competitive inhibition on AChE activity. Moreover, GC/MS results showed that carvacrol and thymol were the major monoterpenes of $P T$ and $S D$ extracts, while limonene and borneol were the main monoterpenes of $R O$ extracts. The strongest antibacterial activities were observed with $\mathrm{EtOH}$ extract of $R O(25.77 \mathrm{~mm})$ against $S$. aureus and with $\mathrm{EtOH}$ extract of $S D(19.52 \mathrm{~mm})$ against $E$. coli. To conclude, all of the plant extracts studied were capable of inhibiting the AChE activity and this observation was compatible with their important biochemical compositions revealed in this study. It was also determined that their great potential as antibacterial agents and non-toxic characteristics make them important 
candidates for pharmaceutical applications like anticholinesterase drugs or starter compounds for synthesizing more effective AChE inhibitors.

\section{Acknowledgments}

The authors would like to thank the Balikesir University Science and Technology Application and Research Center for the Grant provided for this research and Prof. Dr. Serap Doğan for her assistance in plant identification.

\section{Declaration of Conflicting Interests and Ethics}

The authors declare no conflict of interest. This research study complies with research and publishing ethics. The scientific and legal responsibility for manuscripts published in IJSM belongs to the authors.

\section{Authorship contribution statement}

Mehmet Emin Diken: Investigation, Methodology, Supervision, Resources, and Writing original draft. Begumhan Yilmaz Kardas: Investigation, Methodology, Resources, and Writing -original draft.

\section{Orcid}

Mehmet Emin Diken (D) https://orcid.org/0000-0003-3349-939X

Begumhan Yilmaz Kardas (iD https://orcid.org/0000-0002-8446-1116

\section{REFERENCES}

Adewusi, E.A., Moodley, N., \& Steenkamp, V. (2011). Antioxidant and acetylcholinesterase inhibitory activity of selected southern African medicinal plants. S. Afr. J. Bot., 77(3), 638644. https://doi.org/10.1016/j.sajb.2010.12.009

Angelucci, F., Cechova, K., Amlerova, J., \& Hort, J. (2019). Antibiotics, gut microbiota, and Alzheimer's disease. J Neuroinflammation, 16(1), 108. https://doi.org/10.1186/s12974-0191494-4

Assis, C.R.D., Linhares, A.G., Oliveira, V.M., França, R.C.P., Carvalho, E.V.M.M., Bezerra, R.S., \& De Carvalho, L.B. (2012). Comparative effect of pesticides on brain acetylcholinesterase in tropical fish. Sci. Total Environ., 441, 141-150. https://doi.org/10.1 016/j.scitotenv.2012.09.058

Bahadori, M.B., Dinparast, L., Valizadeh, H., Farimani, M.M., \& Ebrahimi, S.N. (2016). Bioactive constituents from roots of Salvia syriaca L.: Acetylcholinesterase inhibitory activity and molecular docking studies. S. Afr. J. Bot., 106, 1-4. https://doi.org/10.1016/j.sa jb.2015.12.003

Bastianetto, S., Ramassamy, C., Dore, S., Christen, Y., Poirier, J., \& Quirion, R. (2000). The Ginkgo biloba extract (EGb 761) protects hippocampal neurons against cell death induced by beta-amyloid. Eur. J Neurosci., 12(6), 1882-1890. https://doi.org/10.1046/j.14609568.2000.00069.x

Blois, M.S., (1958). Antioxidant Determinations by the Use of a Stable Free Radical. Nature, 181(4617), 1199-1200. https://doi.org/10.1038/1811199a0

Bozin, B., Mimica-Dukic, N., Samojlik, I., \& Jovin, E. (2007). Antimicrobial and Antioxidant Properties of Rosemary and Sage (Rosmarinus officinalis L. and Salvia officinalis L., Lamiaceae) Essential Oils. J. Agric. Food Chem., 55(19), 7879-7885. https://doi.org/10.10 $\underline{21 / j f 0715323}$

Cavdar, H., Senturk, M., Guney, M., Durdagi, S., Kayik, G., Supuran, C.T., \& Ekinci, D. (2019). Inhibition of acetylcholinesterase and butyrylcholinesterase with uracil derivatives: kinetic and computational studies. J. Enzyme Inhib. Med. Chem., 34(1), 429-437. https://doi.org/10.1080/14756366.2018.1543288 
Chang, D., Liu, J., Bilinski, K., Xu, L., Steiner, G.Z., Seto, S.W., \& Bensoussan, A. (2016). Herbal Medicine for the Treatment of Vascular Dementia: An Overview of Scientific Evidence. Evidence-based Complementary and Alternative Medi., 2016, 1-15. https://doi.org/10.1155/2016/7293626

Chung, H., Sztal, T., Pasricha, S., Sridhar, M., Batterham, P., \& Daborn, P.J. (2009). Characterization of Drosophila melanogaster cytochrome P450 genes. Proc. Natl. Acad. Sci., 106(14), 5731-5736. https://doi.org/10.1073/pnas.0812141106

Colovic, M.B., Krstic, D.Z., Lazarevic-Pasti, T.D., Bondzic, A.M., \& Vasic, V.M. (2013). Acetylcholinesterase Inhibitors: Pharmacology and Toxicology. Current Neuropharm., 11(3), 315-335. https://doi.org/10.2174/1570159x11311030006

Dave, K. R., Syal, A. R., \& Katyare, S. S. (2000). Tissue Cholinesterases. A Comparative Study of Their Kinetic Properties. Z Naturforsch. C, 55(1-2), 100-108. https://doi.org/10.1515/znc2000-1-219

Depetris-Chauvin, A., Galagovsky, D., Chevalier, C., Maniere, G., \& Grosjean, Y. (2017). Olfactory detection of a bacterial short-chain fatty acid acts as an orexigenic signal in Drosophila melanogaster larvae. Sci. Rep., 7(1). https://doi.org/10.1038/s41598-017-14589$\underline{1}$

Dhifi, W., Mnif, W., Ouerhani, B., \& Ghrissi, K. (2012). Chemical Composition and Antibacterial Activity of Essential Oil from the Seeds of Pistacia terebinthus Grown in Tunisia. J. Essent. Oil-Beari. Plants, 15(4), 582-588. https://doi.org/10.1080/0972060x.20 12.10644092

Dogan, S., Diken, M. E., \& Dogan, M. (2010). Antioxidant, phenolic and protein contents of some medicinal plants. J. Med. Plant Res., 4(23), 2566-2572. https://doi.org/10.5897/jmpr1 $\underline{0.626}$

Doğan, S., Diken, M.E., Turhan, Y., Alan, Ü., Doğan, M., Alkan, M. (2011). Characterization and inhibition of Rosmarinus officinalis L. polyphenoloxidase. Eur. Food Res.Technol., 233, 293-301.

Durak, M.Z., \& Uçak, G., (2015). Solvent optimization and characterization of fatty acid profile and antimicrobial and antioxidant activities of Turkish Pistacia terebinthus L. extracts. Turk J Agric For., 39, 10-19. https://doi.org/10.3906/tar-1403-63

Ellman, G.L., Courtney, K.D., Andres, V., \& Featherstone, R.M. (1961). A new and rapid colorimetric determination of acetylcholinesterase activity. Biochem. pharmacol., 7(2), 8895. https://doi.org/10.1016/0006-2952(61)90145-9

Feng, Y., \& Wang, X. (2012). Antioxidant therapies for Alzheimer's disease. Oxid Med Cell Longev, 2012, 472932. https://doi.org/10.1155/2012/472932

Fernández-López, J., Zhi, N., Aleson-Carbonell, L., Pérez-Alvarez, J.A., \& Kuri, V. (2005). Antioxidant and antibacterial activities of natural extracts: application in beef meatballs. Meat Sci., 69(3), 371-380. https://doi.org/10.1016/j.meatsci.2004.08.004

Fu, A.L., Li, Q., Dong, Z.H., Huang, S.J., Wang, Y.X., \& Sun, M.J. (2004). Alternative therapy of Alzheimer's disease via supplementation with choline acetyltransferase. Neurosci. Lett., 368(3), 258-262. https://doi.org/10.1016/j.neulet.2004.05.116

Gonzalez-Burgos, E., \& Gomez-Serranillos, M.P. (2012). Terpene compounds in nature: a review of their potential antioxidant activity. Curr. Med. Chem., 19(31), 5319-5341. https://doi.org/10.2174/092986712803833335

Johari, M.A., \& Khong, H.Y. (2019). Total Phenolic Content and Antioxidant and Antibacterial Activities of Pereskia bleo. Adv. Pharmacol. Sci., 2019, 7428593. https://doi.org/10.1155/ 2019/7428593

Karimi, A., Majlesi, M., \& Rafieian-Kopaei, M. (2015). Herbal versus synthetic drugs; beliefs and facts. J. Nephropharmacol., 4, 27-30. 
Kilic, T., Yildiz, Y.K., Goren, A.C., Tumen, G., \& Topcu, G. (2003). Phytochemical Analysis of Some Sideritis Species of Turkey. Chem. Nat. Compd., 39(5), 453-456. https://doi.org/10.1023/b:conc.0000011119.53554.9c

Liu, Q.F., Lee, J.H., Kim, Y.-M., Lee, S., Hong, Y.K., Hwang, S., . . Cho, K.S. (2015). In vivo screening of traditional medicinal plants for neuroprotective activity against A $\beta 42$ cytotoxicity by using Drosophila models of Alzheimer's disease. Biol. Pharm. Bull., 38(12), 1891-1901. https://doi.org/10.1248/bpb.b15-00459

Macedo, G.E., Gomes, K.K., Rodrigues, N.R., Martins, I.K., Wallau, G.D.L., Carvalho, N.R. D., . . Posser, T. (2017). Senecio brasiliensis impairs eclosion rate and induces apoptotic cell death in larvae of Drosophila melanogaster.Comp. Biochem. Physiol. Part-C: Toxicol. Pharmacol., 198, 45-57. https://doi.org/10.1016/j.cbpc.2017.05.004

Orhan E.I., Senol, F.S., Gulpinar, A.R., Sekeroglu, N., Kartal, M., \& Sener, B. (2012). Neuroprotective potential of some terebinth coffee brands and the unprocessed fruits of Pistacia terebinthus L. and their fatty and essential oil analyses. Food chem., 130(4), 882888. https://doi.org/10.1016/j.foodchem.2011.07.119

Orhan, I., Aslan, S., Kartal, M., Şener, B., \& Hüsnü Can Başer, K. (2008). Inhibitory effect of Turkish Rosmarinus officinalis L. on acetylcholinesterase and butyrylcholinesterase enzymes. Food chem., 108(2), 663-668. https://doi.org/10.1016/j.foodchem.2007.11.023

Ozarowski, M., Mikolajczak, P.L., Bogacz, A., Gryszczynska, A., Kujawska, M., JodynisLiebert, J., . . Mrozikiewicz, P.M. (2013). Rosmarinus officinalis L. leaf extract improves memory impairment and affects acetylcholinesterase and butyrylcholinesterase activities in rat brain. Fitoterapia, 91, 261-271. https://doi.org/10.1016/j.fitote.2013.09.012

Ozarowski, M., Mikolajczak, P.L., Piasecka, A., Kujawski, R., Bartkowiak-Wieczorek, J., Bogacz, A., . . Seremak- Mrozikiewicz, A. (2017). Effect of Salvia miltiorrhiza root extract on brain acetylcholinesterase and butyrylcholinesterase activities, their mRNA levels and memory evaluation in rats. Physiol. Behav., 173, 223-230. https://doi.org/10.1016/j.phy sbeh.2017.02.019

Perry, N.S.L., Houghton, P.J., Theobald, A., Jenner, P., \& Perry, E.K. (2000). In-vitro Inhibition of Human Erythrocyte Acetylcholinesterase by Salvia lavandulae folia Essential Oil and Constituent Terpenes. J. Pharm. Pharmacol., 52(7), 895-902. https://doi.org/10.12 $\underline{11 / 0022357001774598}$

Ramassamy, C. (2006). Emerging role of polyphenolic compounds in the treatment of neurodegenerative diseases: A review of their intracellular targets. Eur. J. Pharmacol., 545(1), 51-64. https://doi.org/10.1016/j.ejphar.2006.06.025

Rand, M.D., Montgomery, S.L., Prince, L., \& Vorojeikina, D. (2014). Developmental toxicity assays using the Drosophila model. Curr. Protoc. Toxicol., 59(1). https://doi.org/10.1002/0 471140856.tx0112s59

Re, R., Pellegrini, N., Proteggente, A., Pannala, A., Yang, M., \& Rice-Evans, C. (1999). Antioxidant activity applying an improved ABTS radical cation decolorization assay. Free Radic. Biol. Med., 26(9-10), 1231-1237. https://doi.org/10.1016/s0891-5849(98)00315-3

Riaz, B., Zahoor, M.K., Zahoor, M.A., Majeed, H.N., Javed, I., Ahmad, A., . . . Sultana, K. (2018). Toxicity, phytochemical vomposition, and enzyme inhibitory activities of some indigenous weed plant extracts in fruit fly, Drosophila melanogaster. Evid Based Complement Alternat Med, 2018, 2325659. https://doi.org/10.1155/2018/2325659

Şenol, F.S., Orhan, I., Celep, F., Kahraman, A., Doğan, M., Yilmaz, G., \& Şener, B. (2010). Survey of 55 Turkish Salvia taxa for their acetylcholinesterase inhibitory and antioxidant activities. Food chem., 120(1), 34-43. https://doi.org/10.1016/j.foodchem.2009.09.066

Wang, R., Yan, H., \& Tang, X.C. (2006). Progress in studies of huperzine A, a natural cholinesterase inhibitor from Chinese herbal medicine. Acta. Pharmacol. Sin., 27(1), 1-26. https://doi.org/10.1111/j.1745-7254.2006.00255.x 
Yakovleva, E.U., Naimark, E.B., \& Markov, A.V. (2016). Adaptation of Drosophila melanogaster to unfavorable growth medium affects lifespan and age-related fecundity. Biochem. (Moscow), 81(12), 1445-1460. https://doi.org/10.1134/s0006297916120063

Zhang, Y., Liu, X., Wang, Y., Jiang, P., \& Quek, S. (2016). Antibacterial activity and mechanism of cinnamon essential oil against Escherichia coli and Staphylococcus aureus. Food Control, 59, 282-289. https://doi.org/10.1016/j.foodcont.2015.05.032

Zhao, Y., \& Zhao, B. (2013). Oxidative stress and the pathogenesis of Alzheimer's disease. Oxid. Med. Cell. Longev., 2013, 316523. https://doi.org/10.1155/2013/316523 